\title{
Bilgi Teknolojilerinin Belge Yönetimine Etkisi ve Elektronik Belge Yönetimi
}

\author{
Effect of Information Technologies on Records \\ Management and Electronic Records Management
}

\section{Cengiz AYDIN*}

Öz

Bilgi teknolojileri özellikle son on yılda çok hızlı bir gelișme sağlamış ve bu gelişmeler bilgi ve belge yönetimi mesleğini etkilemiştir. Bilgi teknolojilerindeki gelişmeler kurumsal yapı içindeki belge üretimi, depolama, iletim ve paylaşma anlayışlarında önemli değişmelere sebep olmakta, geleneksel belge yönetimi anlayışları yerini modern yönetim anlayışlarına bırakmaktadır. Bu noktada elektronik belgeler çözülmesi gereken önemli sorunlardan biri olarak karşımıza çıkmaktadır. Bu çalışmada, bilgi teknolojilerinin belge yönetimine etkisi ve bu etkinin doğal sonucu olan elektronik belgelerin yönetimi üzerinde durulmuştur.

Anahtar sözcükler: Belge yönetimi, Bilgi yönetimi, Elektronik belge yönetimi, Belgenin yaşam döngüsü, Elektronik belge.

\begin{abstract}
Information technologies have undergone rapid development in the last decade and these developments especially affected the information and records management profession. Developments in information technologies have caused changes in the way of creating, storing, sending and sharing records in organisational structures, and traditional record management has been replaced by a modern understanding of record management. In this respect, the management of electronic records let important problems arise. This study focuses on the effects of information technologies on records management, and thus on electronic record management.

Keywords: Records management, Information management, Electronic records management, Life-cycle of records, Electronic records.
\end{abstract}

\footnotetext{
* Kültür ve Turizm Uzman Yardımcısı; Milli Kütüphane Başkanlığı Bahçelievler 06490 Ankara (aydincen@hotmail.com).
} 


\section{Giriş}

20. Yüzyıl'ın ikinci yarısından itibaren bilgi teknolojilerinde meydana gelen hızlı ilerleme ve gelişme her meslek sahasında olduğu gibi belge yönetimi alanında da ciddi bir değişime ve dönüşüme neden olmuştur. Illerlemenin gereği olarak bu değişime ayak uydurmak mesleki gelecek açısından çok önemlidir. Belge yöneticileri; işlerini daha etkili ve yeterli yapabilmelerine olanak sağlayan bilgi teknolojilerini iyi anlama ve gereklilikleri açısından kendilerini yetiştirmek durumundadır. Bilgi teknolojileri, kağıt belge dışında yönetilmesi gereken belge türlerinin oluşmasına yol açmıştır. Kağıt belge etrafında şekillenen geleneksel belge yönetimi bu yeni durumla birlikte, yeni yaklaşımlar ve çözümler ortaya koymak durumunda kalmıştır. Yeni belge türü olarak elektronik belgelerin yönetilmesinde, kağıt belgelerin yönetiminde uygulanan yöntemlerde aynı şekilde uygulanabilmektedir. Ancak özellikle saklama ve yaşam süreçleri konusunda elektronik belgeler farklılık göstermektedir. Bu bağlamda bir elektronik belge aynı anda farklı yaşam süreçlerinde bulunabilmektedir. Yani elektronik bir belge aynı anda aktif ve yarı aktif olabilmektedir. Elektronik belgeler yönetilirken bu durum göz önünde bulundurulmalıdır. Çünkü önemli bir belge yanlış bir yaşam sürecinin tercihi sebebiyle ulaşılmaz hatta değersiz bir belge haline gelebilmektedir. Bilgi teknolojilerindeki gelişmelerin beraberinde getirdiği bu ve benzeri sorunlar mesleki değişimi kaçınılmaz hale getirmiştir.

\section{Belge Kavramı}

Belge bulunduğu ortama ve türüne bakılmaksızın kurum içindeki her türlü iletişim ağıyla akan bilgidir. Belge kavramı bilgi teknolojilerindeki gelişmelere paralel olarak kavram ve yapı olarak doğal bir değişime ulaşmışıı (Aydın, 2003, s. 31). Bilgiyi yazıya döken birincil araçlar taş tabletler iken, belgeler taşlardan oluşuyordu. Kağıt ve mürekkebin icadıyla, kağıt ortaya çıktı. Günümüzde ise elektronik iletişim araçlarının icadı ve bilgi teknolojilerindeki gelişmelere paralel olarak belgeler elektronik ortamda yeni bir boyut kazandılar.

Birçok belge yönetim programı, on yıllar öncesine dayanan bir kavramsal tanımlama ve faraziyeler çerçevesinde yürütülmekteydi. Bu tanım şöyledir: "Belge kurumun fonksiyonları gereği ürettiği fiziksel yapısı ve şekline bakılmaksızın kayıtlı bilgi demektir" (Dearstyne, 1999, s. 8). Gelişen bilgi teknolojileriyle birlikte yeni değerlendirmeler yapılmaya başlandı. En ileri tanımlardan biri 1997'deki Uluslararası Arşiv Konseyinde (International Council on Archives-ICA) ortaya konmuştur: "Kayıtlı bilginin yapısı ve saklandığı ortama bakılmaksızın üretilmesi ya da alınması, iletilmesi ya da kurumsal veya kişisel bir aktivitenin tamamlanması ve bu aktivitenin delilini 
sağlayacak yapısal yeterlilik, içerik ve metni kapsamaktadır (Dearstyne, 1999, s. 8). Burada daha öncekilerde olduğu gibi "saklandığı ortama bakılmaksızın" vurgusu yapılmaktadır. Aslında belge kavramında yapılan değerlendirmeler günümüzde geçerliliğini sürdürmektedir. Çünkü, tanımda ifade edilen saklandığı ortama bakılmaksızın elektronik belgeyi de kapsamaktadır. Dolayısıyla kavramsal açıdan yeni bir açıklama yapılmaya intiyaç duyulmamaktadır. Ancak yukardaki ifadenin içeriğinin neyi kapsadığı veya neyi tanımladığı bilgi teknolojilerindeki gelişmelerle birlikte aydınlığa kavuşmuştur.

\section{Belge Yönetimindeki Değişimler}

Bilgi teknolojilerindeki gelişmelere paralel olarak belge yönetimi elektronik ortama doğru bir değişim göstermektedir. Bilgi teknolojileri ürünleri olan elektronik posta, faks, sesli posta, bilgisayar disketleri ve bellek kayıtları belge yönetiminde yaşanan değişimi göstermesi açısından önemlidir (Aydın, 2003, s. 33). Bu yeni ürünler beraberinde yeni yaklaşımlar ve çözüm yolları getirmektedir. Elektronik postalar nasıl dosyalanmalıdır, sesli elektronik postalar nasıl kaydedilmelidir, elektronik belgeler ne kadar süreyle saklanmalıdır, elektronik belgeler kağıt belgeler gibi mi yönetilmelidir gibi hususlar bilgi teknolojilerindeki gelişmelerle birlikte ortaya çıkan belge yönetim sorunları olarak sıralanabilir. Bilgi teknolojileri bağlamında yaşanan değişim, bu durumlara çözüm bulma ve yeni belge yönetim anlayışları ortaya koyma zorunluluğunu doğurmuştur.

Teknoloji bağlamında yaşanan önemli değişimlerden biri kağıt belgeler dışında yoğun bir şekilde yönetilmesi gereken bir belge türünün yani elektronik belgenin varlığıdır. Bu belge türüyle birlikte, klasik kağıda dayalı belge türlerinin yönetilmesini ifade eden belge yönetimi yeni bir boyut kazanmıştır. Bilgi teknolojilerinin ortaya koyduğu yeni belge türlerini yönetmek klasik belge yönetim anlayışlarıyla mümkün değildir. Özellikle geleneksel belge yönetiminin önemli iki unsuru; provenans prensibi ve orijinal belge kavramını elektronik belge bağlamında yeniden değerlendirmek gerekmektedir. Provenans aynı kaynaktan gelen belgelerin üretim birimlerine göre düzenlenmesini öngören bir prensiptir. Ancak günümüzün modern ve dinamik örgütlerinde elektronik ortamda bir belgenin provenansını belirlemek oldukça zordur. Bu yüzden provenansı günümüz modern örgütlerine uygularken belge üretimini birimlere değil fonksiyonlara bağlamak gerekmektedir (Kandur, 1999b, s. 19). Orijinal belge kavramı da elektronik belgelerle değişime uğramıştır. Kağıt bir belgenin orjinalliğini tespit etmek oldukça kolaydır. Çünkü fiziksel olarak ele alabildiğimiz kağıt belgenin üzerindeki herhangi bir değişiklikten orijinal olup olmadığını anlayabiliriz. Bununla birlikte üzerinde kolayca değişiklik yapılabilen elektronik belgelerin orijinalliğini tespit etmek zorlaşmaktadır. 
Ancak bilgi teknolojilerindeki gelişmelerle birlikte elektronik belgenin orjinalliğini muhafaza etmesini sağlayacak birtakım güvenlik önlemleri geliştirilmektedir. Bununla birlikte saklama ortamları, yaşam süreçleri ve imha konularında elektronik belgeler farklılık göstermektedir. Elektronik ortamda saklanan bir belge çok çabuk silinebilmektedir. Teknolojideki hızlı değişim sebebiyle teknolojik güncelleme zorunluluğu, güvenilirlik gibi noktalarda çok dikkatli yönetimler geliştirilmesini gerektirir. Bütün bunlar belge yönetiminin yaşadığı değişimi göstermektedir.

\section{Elektronik Belge Yönetimi}

Elektronik belge yönetimi bilgi teknolojilerindeki gelişmelere paralel olarak ortaya çıkan ve bu gelişme oranında kurumsal yapıya yansıyan bir belge yönetim aktivitesidir. Özellikle bilgisayar teknolojisiyle birlikte kurumlar artık belgelerini bilgisayar ortamında üretmekte ve aynı sistem içinde iletimini yapmaktadır. Elektronik belgeler genel olarak bir bilgisayar sistemi bünyesinde üretilen, işlenen ve saklanan belgeleri tanımlar (Kandur, 1999b, s. 16). Elektronik belge yönetimi de bu tür belgelerin yönetilmesini ifade eder. Elektronik belgelerin yönetiminde oluşabilecek olumsuzluklar, yöneticilerin doğru bilgilerle karar almalarında işlevsel devamlılık ve sorumluluk açısından kayıtta birtakım olumsuzlukların oluşması sonucunu doğuracaktır. Bu tip sorunlar kötü bir şekilde yönetilmiş kağıt belge yönetim sistemlerinde olmakta ancak bu elektronik belgelerde daha hızlı ve ani gerçekleşmektedir. Elektronik belgeler, kağıt belgelerde olduğu gibi üretiminden imhasına kadar iyi bir yönetim gerektirir. Elektronik belge yönetimi prensipleri kağıt belgelerin yönetiminden farklı değildir; kaydedilmeye, belirli bir formda tutulmaya, kağıt belgede olduğu gibi ulaşılabilir olmasına gerek vardır. Açıkçası belgeyi bulunduğu ortamda yönetmek tek başına elektronik belge yönetimine yardımcı olamaz. Bununla birlikte elektronik belgeleri üretildiği anda yönetmeye başlamak gereklidir. Aslında denetim elektronik belgeler üretilmeden önce başlanmalıdır. Sistemin tasarım aşamasında her bir belgenin üretimi ve tanımlamalar ile ilgili sistematik bir şekilde saklama süreleri ve imha tarihleri belirlenmeli, güvenli ulaşım ve rahat koruma, belli belgeleri kullanma ve güncellemeyle ilgili konularda yetkilendirmeler yapılmalıdır (Shepherd, 1994, s. 42). Bu nitelemelerin birçoğu rutin belge yönetim aktiviteleridir ve kağıt belgeler için belgenin sonraki yaşam döngüsünde de alınabilir. Ancak elektronik belgelerin üretilmesine başlamadan önce, e-belge yönetim sistemi oluşturulmalıdır.

Elektronik belgeleri oluşturan bir takım unsurlar mevcuttur. Bir belgenin elektronik belge sayılabilmesi için bazı niteliklere sahip olması gerekir. Bunlar; (Duranti, 2001, s. 4): 
> Ortam: Belgenin fiziksel taşıyıcısını ifade eder. Yani elektronik belgenin bilgisayar ortamı, CD-ROM, disket ve benzeri ortamların hangisinde bulunduğunu ifade eder.

$>$ Içerik: Belgenin yerine getirilen fonksiyon gereği sahip olduğu içerik veya amaçladığı mesajı gösterir.

> Fiziksel ve entelektüel şekil/form: Belgenin iletilmesini sağlayan ifade kurallarının bütünüdür.

> Faaliyet: Belgenin hangi faaliyet sonucu oluştuğunu anlatır.

> Arşivsel ilgi (bağ): Her bir belgeyi öncekine ve sonrakine bağlayan ilişkiler bütünüdür.

> Yasal ve idari çerçeve: Belgenin üretildiği yasal, yönetimsel ve işlevsel çerçevedir.

\section{Elektronik Belgelerin Üretimi}

Elektronik belgeler genelde bilgisayar sisteminde değişik program ve yapılar içinde farklı birimlerde üretilen her türlü belgeyi kapsamaktadır. Elektronik belgeler ya tek bir uygulama programında ya da birbirine bağlı ve uyumlu birden fazla programda oluşturulabileceği gibi, bir elektronik belge birden fazla türde belge yapısı içerebilmektedir (Kandur, 1999b, s. 16). Elektronik belgelerin üretim aşamasında kontrolü, kağıt belgelere göre daha zor bir süreçtir. Bu sebeple belgeler üretilmeden önce sistem tanımlanmalı ve imhasına kadar giden süreç belirlenmelidir.

Günümüz dinamik kurumsal yapılarında bilgi teknolojilerindeki gelişmelere bağlı olarak elektronik belgeler yoğun bir şekilde üretilmektedir (Menkus, 1996, s. 3). Elektronik üretim sadece kurum içi aktiviteler sonucunda olmamakta, elektronik posta, web gibi yollarla da yapılmaktadır. Elektronik postalar yapısal farklılıkları gereği değişik bir yönetim gerektirmektedir. Aynı şekilde web ortamında sürekli güncelleme neticesinde yoğun bir belge üretimi olmaktadır. Bunlar kurumsal iş aktiviteleri sonucunda üretilen belgelerden ayrı yönetilmelidir. Web belgelerinin aktif bir yapıda olması sebebiyle önceki hali, yeni haliyle bağlantıı bir şekilde ele alınmalıdır.

\section{Elektronik Belgelerin Muhafazası}

Elektronik belgelerin yaşam sürecinde bilginin düzenlenmesinde, kolay erişebilirliği sağlamak çok önemlidir. Bunun yanısıra, elektronik belgeler, diğerlerine göre farklı bir saklama ortamı gerektirir. Yani kağıt belgeler için sadece okuyacak bir göz yeterliyken, elektronik belgelerden bir bilgi kaynağı olarak yararlanmak için makinelere intiyaç duyulmaktadır. Elektronik belgeleri muhafaza aşamasını sağlıklı yürütebilmek için öncelikle şu hususların tespit edilmesi gerekmektedir; (Rhodes, 1991, s. 16) 
$>$ Depolanan Malzeme: Ne tür malzemenin muhafaza edileceği yani malzemelerin hangi formatta olacağıdır. Veri, grafik, video gibi formatlardan hangisini içereceği tespit edilmelidir.

> Saklama Süresi: Elektronik belgenin ne kadar süreyle saklanmasının ve kullanım intiyacının ne kadar süreceği ve muhafaza ortamları belirlenmelidir.

> Kullanım: Kullanıcıların belgeye ne şekilde ulaşacağının tespiti gereklidir. Yani çevrimiçi, anında, tüm metnin iletimi gibi şekillerden bir/birkaçı belirlenmelidir.

> Sayısallaştırma: Elektronik belgenin yaşam döngüsünün hangi aşamasında sayısal ortama aktarılacağının tespiti belge muhafaza aşamasının sağlıklı yürütülebilmesi için önemlidir.

> Saklama Ölçütleri: Hız, fiyat, kapasite, kolay taşınabilirlik, süreklilik gibi uzun dönem saklama seçeneklerinin belirlenerek sağlanması gerekmektedir.

Elektronik belgelerin üretildiği yazılım ve donanımın korunması ve gelişen bilgi teknolojileri bağlamında yenilenmesi gerekmektedir. Elektronik belgelerin muhafazasında ilk önemli husus, bulunduğu donanımdır. Buna bağlı olarak elektronik ortamdaki veriler yazılım veya donanım eksikliği nedeniyle belli bir zaman sonra kullanılmaz duruma gelebilir; optik diskler kimyasal bileşimine göre sürekliliği değişebilmektedir (Shepherd, 1994, s. 43). Bazı firmalar sadece yazılabilen CD-ROM'lar için yüz yıl ömür biçmektedir; ama yirmi beş yıl sonra kullanım ömürleri büyük oranda sona ermektedir. Yazılıp silinebilen CD-ROM'ların 10-15 yıl içinde ömürleri sona ermektedir. Diğer yandan sabit diskler üzerindeki veriler kullanılamaz duruma gelebilir. Değişen teknolojinin nasıl etkin olduğu düşünülürse, geleceğin arşivleri makinelerin okuyabildiği, belgelerin kullanıcılar tarafından ulaşılmasını sağlamak için bir makine müzesi oluşturulmasına intiyaç duyulacaktır. Bunun mümkün olmayacağı düşünülürse gelişen bilgi teknolojilerine paralel olarak oluşturulan elektronik belge yönetim sisteminin teknolojiye uygun bir şekilde geliştirilmesi gerekmektedir (Aydın, 2003, s. 41). İkinci önemli husus yazııımdır. Elektronik veriler yazılıma göre değişebilir ve yazılımın yaşam süresi genellikle iki yıldan daha azdır. Bu yüzden yazılımdaki gelişmeler takip edilerek eski elektronik belgelerin yeni yazılımlarla uyumlu bir şekilde çalışması sağlanmalıdır.

\section{Elektronik Belgelerin Imhası}

Elektronik belgelerin imhası, tam, güvenilir ve gerçek elektronik belgelerin aktif iş süreci içinde gereksinim duyulmayan belgelerin imhası olarak 
tanımlanabilir. Kolayca yeniden düzenlenebilen, güncellenebilen oldukça hassas olan elektronik belgeler genellikle silinir ve bulundukları ortam yeniden kullanılabilir, çünkü oldukça pahalı bir ortamda muhafaza edilirler (U.S. Federal Highway Administration [FHWA], 2003). Bu yüzden elektronik belgelerin imhası yaşam süreçlerinin mümkün olan en erken safhasında belirlenmelidir. Elektronik belge yönetiminde belgelerin imha süreci, insanların bilgiyi kaydetme ve kullanma yolları hakkındaki temel gerçek etrafında dönmeye devam etmektedir. Kurumsal yapı içinde sorumlu kişiler çeşitli belgeleri üretecekler, bu belgelerden gerekli olanları alacaklar ve yaşam döngüsünün son aşamasına geldiği düşünülenleri de bir sistematik içinde imha edeceklerdir. Elektronik belgelerin imhası süreci yasal ve kurumsal gereklilikler çerçevesinde belirlenmelidir. Düzenli imha elektronik belge yönetim yapısının yönetilebilirliğini, güncel olmayan belgelerin karışmamasını sağlarken etkili bir geri iletim sisteminin oluşmasına imkan verir (Aydın, 2003, s. 42). Elektronik belge yönetimindeki bu son süreci gerçekleşmeden önce, kullanım paylaşımı verilmiş dosyalarda üreten ya da yetkili olan kişiyle koordineli olarak yürütülmeli ve izni alınmalıdır. Eğer elektronik ortamda üretilen birtakım elektronik belgelerin kağıt nüshaları oluşturulup dosyalama sistemine kaydedilmişse, elektronik belgelerle ilgili ayıklama ve imha işlemi yapılabilir. (Dickman, 2002, s. 54).

\section{Elektronik Belgelerin Yaşam Döngüsü}

Belgenin yaşam döngüsü, belgenin üretilmesinden, kullanılması, saklanması, aktif olmayan dosyaların saklama planları, aktif dosyalara transferi ve son olarak imhasını içine alan süreçtir (Gill, 1998, s. 5); yani belgenin doğumundan ölümüne kadar sürdürdüğü hayatın ifadesidir. Belge yaşamının herhangi bir noktasında nerede olacağı, belgenin bulunduğu ortamın ne zaman değişeceği, ne zaman ikinci nüshasının oluşacağı, değiştirileceği, pasif hale geleceğiyle ilgilidir. Yaşam döngüsü kavramı kağıt belgeler için belgenin üretimi, dağıtımı, korunması, kullanılması ve imhasını içermektedir. Belge yönetiminin temelinde var olan bu tanımların, elektronik belge kavramı ortaya çıkınca gözden geçirilmesi zorunluluk haline gelmiştir. Zira bu ifadeler elektronik belgenin yaşam döngüsünü tam olarak karşılamamaktadır. Kağıt belgenin yaşam döngüsü, üretilmesinden itibaren başlarken, elektronik belgelerin yaşam döngüsü bilgisayara dayalı bilgi sisteminin tasarım aşamasında başlamalıdır; belgenin saklama süresi ve imhası, belgenin sınıflandırılması ve sistem içinde bilginin akışıyla ilgili kararlar bu aşamada alınmalıdır. Eğer yaşam döngüsü kavramı bir yönüyle kullanım sıklığıyla tanımlanıyorsa, elektronik belgelerin aynı anda aktif, yarı-aktif ve pasif 
safhalarda yaşamaları mümkündür (Kandur, 1999a, s. 40). Bu sebeple elektronik belge yönetim sistemi oluştururken bu husus dikkatle göz önünde bulundurulmalıdır. Aksi taktirde belgelere zamanında ve etkin bir şekilde ulaşmada ciddi sorunlar yaşanabilir.

\section{Sonuç}

Bilgi teknolojileri, son on yılda çok hızı gelişme göstermiş ve büyük çaplı bilgisayar ağları, elektronik belgelerin kopyalarının uzak bir mekâna hızlı bir şekilde iletme imkanı tanımışırı. Böylece kağıt kopyalara olan intiyaç belli oranda ortadan kalkmaktadır. Internet'teki web sayfaları, kurumsal politika ve işlevlerin dinamik bir şekilde ve kopyalarını saklamaya intiyaç duymadan kullanıcıların ulaşmasına imkan tanımaktadır. Belgeleri kağıt kullanmadan üretip saklama, imha etme ve belge merkezine bir kopyasını gönderme özelliklerine sahip elektronik belge yönetim programları bilgi teknolojilerindeki gelişmelerle birlikte ortaya çıkmıştır. Artık kurumların işlevleri gereği üretilen belgelerin, iletim ve saklanması daha etkin bir biçimde bilgisayar sistemleri aracılığıyla yerine getirilmektedir. Bilgisayarda kelime işlemci uygulamalarıyla yazışmaları üretmek, kalem, kağıt veya daktiloyla üretmekten daha verimli olmaktadır; bu bağlamda elektronik belge yönetimi üzerinde durulması ve beraberinde karşılaşılan sorunların, bir belge yönetim aktivitesi olarak çözülmesi gereği ortaya çıkmaktadır. Çağımızın bu yeni ürününü etkin bir şekilde yönetmek kurumsal başarı açısında çok önemlidir.

\section{Kaynakça}

Aydın, C. (2003). Bilgi teknolojilerindeki gelişmeler ışığında arşivcinin değişen rolü. Yayımlanmamış yüksek lisans tezi, Marmara Üniversitesi, İstanbul.

Dearstyne, B.W. (1999). Records management of the future: Anticipate, adapt, and succeed. Information Management Journal, 33 (4), 4-17.

Dickman, J.C. (2002). Information preservation: Changing role. Information Management Journal, 36 (5), 54-59.

Duranti, L. (2001). The impact of digital technology on archival science. Archival Science, 1 (1), 39-55.

FHWA. (U.S. Federal Highway Administration). (2003, Ocak). Files management and records disposition manual. Ocak 2003 tarihinde http://www.fhwa.dot.gov/legsregs/directives/orders/m13241/13241ac4.h tm adresinden erişildi. 
Gill, S.L. (1998). File management and information retrieval systems.

Colorado: Libraries Unlimited.

Kandur, H. (1999a). Management of electronic records: Educating archivist and records managers. Arşiv Araştırmaları Dergisi, 1 (1), 35-45.

Kandur, H. (1999b). Elektronik arşivler ve arşivcilik mesleğinin geleceği. "Bilgi Çăgı, Bilgi Merkezler ve Bilgi Teknolojileri” Sempozyumu bildirileri: 7-8 Mayıs 1997 içinde (ss. 15-21). Ankara: Ankara Üniversitesi.

Menkus, B. (1996). Defining electronic records. Records Management Quarterly, 30 (1), 1-6.

Rhodes, S.B. (1991). Archival and records management automation. Records Management Quarterly, 25 (1), 12-43.

Shepherd, E. (1994). Managing electronic records. Records Management Journal, 4 (3), 39-49. 